\title{
Determinação da vazão de projeto para a escolha dos hidrômetros de edificações residenciais com medição individualizada
}

\author{
Determining the flow rate for choosing water meters of \\ residential buildings with individual metering
}

\section{Marina Melo Luiz Amorim Marcus André Siqueira Campos}

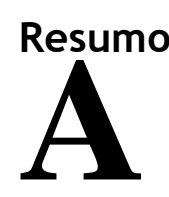

objetivo comparar os valores de vazões de projeto com os valores de vazões obtidos em apartamentos em operação. Foi realizada uma investigação em 20 unidades habitacionais, nas quais as vazões foram identificadas e seus perfis de consumo de água e a distribuição de vazões reais ao longo do tempo definidos. Foram comparadas as vazões calculadas pelo método proposto por Gonçalves (1986), além dos métodos utilizados nas normas brasileiras, portuguesa e europeia, com as vazões reais medidas e indicadas em padrão técnico, através da utilização de técnicas de estatística descritiva e de modelagem probabilística dos dados. Foi possível verificar que os valores derivados do método probabilístico foram os que mais se aproximaram das medições reais. Concluiu-se que o uso do método probabilístico reduz a vazão nominal dos hidrômetros escolhidos, o que pode aumentar a precisão e, consequentemente, o volume medido para a concessionária local. Contribui também para melhorar os procedimentos de avaliação do dimensionamento de hidrômetros.

Palavras-chave: Medição individualizada. Dimensionamento de hidrômetros. Perfil de consumo. Vazões reais.

\begin{abstract}
The implementation of the individual measurement system requires the correct adjustment of the water meters. Thus, the determination of project flow rates is one of the premises for proper system performance. From this point of view, this article aims to compare the design flow values with the flow values obtained in apartments in operation. An investigation was carried out into 20 housing units, in which the flows were identified and their water consumption profiles and the actual flow distribution over time defined. We compared the flows calculated by the method proposed by Gonçalves (1986) in addition to the methods used in the Brazilian, Portuguese and European standards with the actual flows measured and indicated in a technical standard, using descriptive statistics techniques and using probabilistic data modeling. It was possible to verify that the values derived from the probabilistic method were the closest to the real measurements. It was concluded that the use of probabilistic method reduces the nominal flow of the chosen water meters, which can increase the accuracy and, consequently, the measured volume for the local utility. It also contributed to improve the procedures for assessing the design of water meters.
\end{abstract}

Keywords: Individual metering. Hydrometer sizing. Typical flow rate. Consumption profile. 


\section{Introdução}

Fornecer água em qualidade e quantidade suficientes para atender às demandas diárias das diversas atividades tem sido um desafio em diversos países pelo mundo (RUSCA et al., 2017; LONDOÑO; SEGRERA; JARAMILLO, 2017). De acordo com a UN-Water (UNITED..., 2015), há 663 milhões de pessoas no mundo que não têm acesso aos serviços de água potável.

Diante disso, vários estudos de casos em países como Grécia (KORKANA et al., 2016a, 2016b; KARATHANASI; PAPAGEORGAKOPOULOS, 2016), Inglaterra (SAVIC; FERRARI, 2014; WHIGHT; STOIANOV; PARPAS, 2014), Irlanda (HAJEBI et al., 2014), Itália (ALVISI; FRANCHINI, 2014; DE PAOLA et al., 2014a, 2014b; DI NARDO et al., 2014) e Portugal (GOMES; SOUSA; MARQUES, 2014; GOMES et al., 2015) apontam investimentos em ações e técnicas para a melhoria do monitoramento e do controle de sistemas de abastecimento com o propósito principal de mitigar perdas de água.

Com o intuito de gerenciar a demanda de água nas cidades, vem-se desenvolvendo um conjunto de atividades para se economizar água nos centros urbanos, principalmente o consumo de água de uso residencial (BARRETO; MEDEIROS, 2008). No contexto dos sistemas prediais, soluções para a melhoria do desempenho têm sido incorporadas, como, por exemplo, a conscientização de usuários, a aplicação de equipamentos economizadores, o uso de águas pluviais e a medição individualizada.

A gestão da demanda domiciliar abraça todas essas práticas voltadas para a redução do consumo final pela população com o objetivo de mudança de hábito no uso da água, como também para controlar e contabilizar adequadamente o consumo. Como consequência desse cenário, Ilha, Oliveira e Gonçalves (2010) apontam que, há alguns anos, os próprios usuários de edifícios habitacionais vêm solicitando sistemas individualizados de medição de água, tal como ocorre com os sistemas prediais de energia e de gás.

Tradicionalmente, nas edificações multifamiliares brasileiras, a água era medida por meio de um único medidor, localizado no alimentador predial (COELHO; MAYNARD, 1999), rateando a conta de água para os diversos condôminos. Devido a uma pressão da própria sociedade, observou-se, nos últimos anos, a instalação de um hidrômetro para cada unidade habitacional, com emissão de contas separadas para cada apartamento (medição individualizada).

Essa prática, além de permitir que o pagamento seja proporcional ao consumo registrado no hidrômetro, consegue setorizar a medição, identificando o perfil de consumo dos habitantes. Outra consequência é o incentivo da adoção de medidas, por parte dos próprios usuários, para reduzir desperdícios, como, por exemplo, a substituição de aparelhos sanitários e a eliminação de vazamentos.

A implantação do sistema de medição individualizada postula o correto dimensionamento dos equipamentos. Hidrômetros mal dimensionados podem dificultar a detecção de vazamentos, prejudicar a pressão de abastecimento e, ainda, segundo Pereira (2007), resultar na submedição do consumo, o que ocorre quando as vazões no ramal de alimentação são, em sua maioria, inferiores à vazão mínima dos hidrômetros e, portanto, não detectadas.

A NBR 5626 (ABNT, 1998) recomenda o emprego de métodos empíricos para o estabelecimento de vazões de projeto em sistema predial de água fria, entre eles o método da raiz quadrada, no qual a técnica de determinação das vazões de projeto se baseia na utilização de expressões matemáticas, gráficos, tabelas e ábacos. Contudo, de acordo com Ilha, Oliveira e Gonçalves (2010), esse método não é adequado, pois não considera que as vazões de projeto dependem das atividades dos usuários que, por sua vez, são função do tipo do edifício e das características do usuário, entre outros.

Ainda dentro do grupo dos modelos empíricos, encontram-se os métodos europeu e português. O modelo europeu foi criado com o objetivo de padronizar o dimensionamento dos sistemas prediais de água fria nos países-membros e, para isso, o Comitê Europeu de Normalização (CEN) criou a EN 806-3 (EUROPEAN..., 2006)), que traz um método simplificado.

Portugal, embora faça parte da União Europeia, mantém o uso do Regulamento Geral dos Sistemas Públicos e Prediais de Distribuição de Água e de Drenagem de Águas Residuais (PORTUGAL, 1996) para esse fim.

Não obstante, na década de 1980, métodos probabilísticos estavam sendo desenvolvidos no Brasil, como o modelo proposto por Gonçalves (1986), o qual sugere determinar as vazões de projeto empregando-se tabelas com valores de expressões matemáticas, 'pesos' e gráficos, utilizando função de distribuição de probabilidades binomial. 
Diante disso, identificar as vazões de abastecimento em edificações multifamiliares com medição individualizada assume grande relevância na análise dos métodos de determinação de vazões de projeto.

Sendo assim, o objetivo geral deste trabalho é comparar os valores de vazões de projeto com os valores de vazões obtidos em apartamentos em operação.

\section{Metodologia}

\section{Escolha e descrição dos objetos de estudo}

Os seguintes critérios foram utilizados para a escolha dos objetos de estudo: a edificação deveria ser multifamiliar vertical, com sistema de medição individualizada cadastrado pela concessionária local (Saneago); os apartamentos que compõem a edificação deveriam ter configuração de 3 quartos e 2 banheiros ( 2 chuveiros elétricos), facilidade de acesso aos projetos e medição individualizada.

Para a seleção das unidades nos edifícios, realizou-se um levantamento no cadastro comercial da companhia de serviços de saneamento para excluir os consumidores com consumo anômalo ou muito variável, conforme recomendado pela NBR 15538 (ABNT, 2014). Agregado a isso, buscou-se selecionar apartamentos que contemplassem diversas zonas de pressão no edifício.

No total, 20 apartamentos foram utilizados nesta pesquisa. Metade desses apartamentos estava em uma edificação na cidade de Goiânia, denominado edifício A. A outra metade foi selecionada em uma edificação na mesma cidade e do mesmo padrão, denominada aqui edifício B. Para o edifício A, foram selecionadas as unidades 104, 203, 302, 404, 501, 603, 703, 801, 804, 1101 , Para o edifício B, os apartamentos selecionados foram 203, 401, 903, 1004, 1204, 1301, 1501, 1603, 1902, 2002. Ressalta-se que o edifício A não possuía válvula redutora de pressão e o edifício B possuía duas: uma localizada no $15^{\circ}$ andar e outra localizada no $7^{\circ}$ andar.

O edifício A possui 11 pavimentos, com 4 apartamentos por andar. Cada unidade habitacional é composta de três quartos, sendo uma suíte; dois banheiros; um lavabo; um sanitário de serviço; uma cozinha; uma área de serviço; e uma sala de estar/TV/jantar.

A única exceção à planta baixa padrão apresentada foi o apartamento 1101, o qual é uma unidade duplex composta de quatro quartos, sendo três suítes; cinco banheiros; uma cozinha com duas pias; uma área de serviço; uma sala de estar/TV/jantar; e área descoberta com piscina.

O edifício B possui 24 pavimentos e 4 apartamentos por andar. O apartamento padrão é composto de três quartos, sendo uma suíte plena e duas suítes americanas, dois banheiros, um lavabo de serviço, uma cozinha, uma área de serviço e uma sala de estar/TV/jantar. Os aparelhos presentes nos apartamentos analisados são apresentados no Quadro 1.

\section{Determinação de vazão de projeto}

Na determinação das vazões utilizaram-se dois métodos de dimensionamento: raiz quadrada, apresentado na NBR 5626 (ABNT, 1998), e probabilístico, proposto por Gonçalves (1986).

$\mathrm{Na}$ aplicação do método desenvolvido por Gonçalves (1986), consideraram-se 2 pessoas em cada banheiro (suíte ou social) e 1 pessoa para cozinha e área de serviço. Foram utilizadas como dados de entrada as informações advindas de Ilha, Oliveira e Gonçalves (2010), as quais são apresentadas na Tabela 1. Os usos per capita são apresentados na Tabela 2.

Embora existisse o ponto de água para a instalação do filtro, diversos apartamentos não instalaram esse equipamento. Além disso, informações como duração, vazão e usos per capita não foram encontradas na bibliografia. Dessa forma, optou-se por não considerar o uso do filtro. Como a vazão é muito baixa, acreditase que a ausência desse equipamento não comprometa a análise realizada.

As vazões de projeto no método probabilístico foram estabelecidas considerando duas situações - duração do período de pico com $1 \mathrm{~h}$ e $1,5 \mathrm{~h}$, com fator de falha global de 0,01 (1\%) e fator de falha local máximo de $0,05(5 \%)$-, baseadas nos estudos que utilizaram o método (OLIVEIRA et al., 2011; OLIVEIRA, 2007; ILHA; OLIVEIRA; GONÇALVES, 2008, 2010). 
Quadro 1 - Identificação dos aparelhos sanitários nas unidades padrão dos edifícios A e B

\begin{tabular}{|c|c|c|c|}
\hline \multicolumn{2}{|c|}{ Edifício A } & \multicolumn{2}{|c|}{ Edifício B } \\
\hline Ambientes & Aparelho sanitário & Ambientes & Aparelho sanitário \\
\hline \multirow{3}{*}{ banheiro social } & $\begin{array}{l}\text { bacia sanitária (caixa de } \\
\text { descarga) }\end{array}$ & \multirow{3}{*}{$\begin{array}{l}\text { banheiro suíte } \\
\text { americana }\end{array}$} & $\begin{array}{l}\text { bacia sanitária (caixa de } \\
\text { descarga) }\end{array}$ \\
\hline & lavatório & & lavatório \\
\hline & chuveiro elétrico & & chuveiro elétrico \\
\hline \multirow{3}{*}{ banheiro suíte } & $\begin{array}{l}\text { bacia sanitária (caixa de } \\
\text { descarga) }\end{array}$ & \multirow{3}{*}{ banheiro suíte } & $\begin{array}{l}\text { bacia sanitária (caixa de } \\
\text { descarga) }\end{array}$ \\
\hline & lavatório & & lavatório \\
\hline & chuveiro elétrico & & chuveiro elétrico \\
\hline \multirow[t]{2}{*}{ lavabo } & $\begin{array}{l}\text { bacia sanitária (caixa de } \\
\text { descarga) }\end{array}$ & \multirow[t]{2}{*}{ lavabo } & $\begin{array}{l}\text { bacia sanitária (caixa de } \\
\text { descarga) }\end{array}$ \\
\hline & lavatório & & lavatório \\
\hline \multirow{2}{*}{ cozinha } & pia & \multirow{2}{*}{ cozinha } & pia \\
\hline & filtro & & filtro \\
\hline \multirow{2}{*}{ área de serviço } & tanque & \multirow{2}{*}{ área de serviço } & tanque \\
\hline & lavadora de roupas & & lavadora de roupas \\
\hline banheiro de serviço & $\begin{array}{l}\text { bacia sanitária (caixa de } \\
\text { descarga) }\end{array}$ & & \\
\hline
\end{tabular}

Tabela 1 - Durações de descargas e vazões dos aparelhos sanitários

\begin{tabular}{c|c|c|c|c|c|c|c|c|c}
\hline \multirow{2}{*}{$\begin{array}{c}\text { Aparelho } \\
\text { sanitário }\end{array}$} & \multicolumn{2}{|c|}{ Duração da descarga (s) } & \multicolumn{3}{c|}{ Vazão (l/s) } & \multicolumn{3}{c}{ Usos per capita } \\
\cline { 2 - 9 } & Mínimo & $\begin{array}{c}\text { Mais } \\
\text { provável }\end{array}$ & Máximo & Mínimo & $\begin{array}{c}\text { Mais } \\
\text { provável }\end{array}$ & Máximo & Mínimo & $\begin{array}{c}\text { Mais } \\
\text { provável }\end{array}$ & Máximo \\
\hline Lv & 15 & 25 & 30 & 0,05 & 0,07 & 0,1 & 1 & 1 & 2 \\
Bs & 45 & 68 & 85 & 0,08 & 0,1 & 0,15 & 0 & 1 & 1 \\
Ch & 300 & 480 & 900 & 0,05 & 0,09 & 0,12 & 0 & 1 & 1 \\
Pia & 15 & 30 & 60 & 0,1 & 0,12 & 0,2 & 3 & 4 & 6 \\
MLR & 480 & 720 & 960 & 0,1 & 0,13 & 0,19 & 0 & 1 & 2 \\
Tq & 20 & 30 & 40 & 0,1 & 0,15 & 0,2 & 0 & 1 & 1 \\
\hline
\end{tabular}

Fonte: Itha, Oliveira e Gonçalves (2010).

Tabela 2 - Valores do número de usos per capita

\begin{tabular}{c|c|c|c}
\hline \multirow{2}{*}{ Aparelho sanitário } & \multicolumn{3}{|c}{ Usos per capita } \\
\cline { 2 - 4 } & Mínimo & Mais provável & Máximo \\
\hline LV social & 1 & 1 & 2 \\
LV suíte & 0 & 1 & 1 \\
BS social & 0 & 1 & 1 \\
BS suíte & 0 & 1 & 1 \\
CH social & 0 & 1 & 1 \\
CH suíte & 0 & 1 & 1 \\
PIA & 3 & 4 & 6 \\
LR & 0 & 1 & 2 \\
TQ & 0 & 1 & 1 \\
\hline
\end{tabular}

Fonte: Itha, Oliveira e Gonçalves (2010).

\section{Instrumentação}

Devido a sua precisão, principalmente em baixas vazões, utilizou-se o medidor tipo volumétrico de classe metrológica $\mathrm{C}$ por atender satisfatoriamente ao objetivo proposto. $\mathrm{O}$ medidor empregado na pesquisa hidrômetro volumétrico, classe C, Diehl Metering, modelo Altaïr V4 com vazão nominal (Qn) de 1,5 m³/h. Esses hidrômetros foram instalados, substituindo os existentes, durante o período da pesquisa. 
Neste estudo, o medidor foi acoplado ao equipamento modular denominado Izar Pulse $\mathrm{H}$, transformando-o em medidor equipado com telemetria para posterior instalação de datalogger modelo LogBox-DA, da fabricante Novus. Como parâmetros de configuração, utilizou-se aquisição de vazões instantâneas em intervalo de aquisição de $10 \mathrm{~s}$.

Realizou-se também a medição da pressão, efetuada com manômetros analógicos. Os dados de pressão foram coletados às $7 \mathrm{~h}, 12 \mathrm{~h}$ e $19 \mathrm{~h}$ - horários de pico - durante três ocasiões. Utilizaram-se como ponto de acoplamento do manômetro as torneiras existentes na escada de incêndio no edifício A e as torneiras do tanque das unidades no edifício B.

\section{Coleta de dados e monitoramento}

A coleta de dados deste estudo foi realizada no edifício A no período de 15/12/2017 a 15/01/2018 e no edifício B de 15/01/2018 a 15/02/2018.

As coletas dos dados dos dataloggers ocorriam entre três ou quatro dias, sempre em dias úteis. Após essa coleta, averiguavam-se a configuração e a duração da bateria para reinício do sistema de coleta, gastando-se nesse procedimento de $6 \mathrm{~min}$ a $7 \mathrm{~min}$, por aparelho, a cada visita. O período de aquisição desses equipamentos foi programado para um intervalo de $10 \mathrm{~s}$ com o registro da vazão instantânea.

As vazões de cada uma das 20 unidades habitacionais foram identificadas. Classificaram-se a frequência e os tempos de permanência em cada uma das faixas de vazão consideradas pelo processo de agrupamento dos dados obtidos pelo sistema de aquisição de vazões instantâneas.

\section{Tratamento e análise de dados}

No total, foram registrados 2.655.891 e 2.665.291 de dados respectivamente para os edifícios A e B. Determinou-se, então, a faixa de vazões, identificando-se as vazões mínimas, médias e máximas para cada uma das 20 unidades habitacionais. Também se levantaram a frequência, os tempos de permanência em cada uma das faixas de vazão consideradas e o volume total correspondente, além do consumo médio diário.

As faixas de vazão consideradas foram determinadas a partir dos dados registrados em campo e seguindo-se a recomendação da NBR 15538 (ABNT, 2014). As faixas foram até 6 1/min, acima de 60 1/min e uma faixa para cada um dos valores intermédios entre esses.

Após a identificação da ocorrência das vazões reais, as probabilidades de incidências das vazões de projeto foram avaliadas em relação ao perfil encontrado em campo, bem como a detecção de quais hidrômetros seriam recomendados foi feita tanto pela análise das medições reais quanto pelas vazões de dimensionamento.

A indicação dos hidrômetros foi feita seguindo as orientações da Portaria $\mathrm{n}^{\circ} 246$ (MINISTÉRIO...; INSTITUTO..., 2000), levando-se em conta as vazões apontadas para os medidores de classes metrológicas B e C, os quais são os mais utilizados pelas concessionárias de serviços de saneamento em geral, inclusive pela prestadora local.

Para o dimensionamento dos hidrômetros utilizando as vazões reais, estabeleceram-se três critérios, listados a seguir. A obediência desses parâmetros tende a assegurar as condições adequadas para o funcionamento do medidor.

(a) a vazão máxima do sistema não deve ultrapassar a vazão máxima (Qmáx) do medidor;

(b) a vazão de operação deve manter-se inferior à vazão nominal (Qn) do equipamento; e

(c) a vazão mínima de operação deve ser superior à vazão mínima (Qmín) do medidor.

Em virtude de as vazões levantadas em campo serem consideradas variáveis quantitativas e se caracterizarem por serem elementos frequentes, os dados de vazão obtidos para cada unidade foram agrupados nas seguintes categorias (em litros por segundo): 0,1 1/s a 0,7 1/s, de modo a se construir uma distribuição de frequência para essas classes. Cada um desses valores representa uma classe. Por exemplo, 0,1 representa a classe $0,0-0,15$. Utilizou-se essa organização tabular, em termos de distribuição de frequência, na sumarização dos dados de vazões por unidade (Tabela 3). 
Tabela 3 - Distribuição de frequência para as vazões a serem coletadas

\begin{tabular}{c|c|c|c|c|c|c|c}
\hline \multirow{2}{*}{ Unidades } & \multicolumn{7}{c}{ Classes } \\
\cline { 2 - 8 } & $\mathbf{0 - 0 , 1 5}$ & $\mathbf{0 , 1 5 - 0 , 2 5}$ & $\mathbf{0 , 2 5 - 0 , 3 5}$ & $\mathbf{0 , 3 5 - 0 , 4 5}$ & $\mathbf{0 , 4 5 - 0 , 5 5}$ & $\mathbf{0 , 5 5 - 0 , 6 5}$ & $\mathbf{0 , 6 5 - 0 , 7 5}$ \\
\hline 1 & $\mathrm{f} 11$ & $\mathrm{f} 12$ & $\mathrm{f} 13$ & $\mathrm{f} 14$ & $\mathrm{f} 15$ & $\mathrm{f} 16$ & $\mathrm{f} 17$ \\
2 & $\mathrm{f} 21$ & $\mathrm{f} 22$ & $\mathrm{f} 23$ & $\mathrm{f} 24$ & $\mathrm{f} 25$ & $\mathrm{f} 26$ & $\mathrm{f} 27$ \\
\hline
\end{tabular}

Os valores fij representam a frequência da vazão (quando essa ocorre) para a classe $j$ e a unidade $i$. A partir desses valores, foram calculadas a média ponderada, visto haver a necessidade de levar em conta a importância ou o peso relativo das vazões, a moda, a mediana, o percentil 99 (P99), a estimativa de densidade Kernel (Kernel Density Estimation) (SILVERMAN, 1996) e a soma de Riemann para a distribuição dos dados (ROSS, 2010).

Neste estudo utilizou-se o kernel gaussiano, comumente empregado como kernel padrão nesse tipo de estimativa, aplicando-se largura de banda $h=0,05$, considerando que, para o kernel gaussiano, a largura de banda está associada ao desvio-padrão da distribuição. Em virtude de o comprimento das classes ser de 1,0 1/s, decidiu-se adotar h a metade desse valor, uma vez que um valor menor provocaria um superajuste, ao passo que um valor maior simplificaria demais a função $f$.

Utilizou-se a soma de Riemann como aproximação para o cálculo de áreas e, por sua vez, essas áreas foram empregadas como estimativa nos cálculos de probabilidades almejados. Em uma função diferencial $f$, uma soma de Riemann $S$ de $f$ em um intervalo $[\mathrm{a}, \mathrm{b}]$ para a partição a $=\mathrm{x} 0<\mathrm{x} 2<\ldots<\mathrm{xn}=\mathrm{b}$ é definida como apontado na Equação 1.

$S=\sum_{i=1}^{n} f\left(x_{i}\right)\left(x_{i}-x_{i-1}\right), x_{i-1} \leq x \leq x_{i}$

A partir daí, foi possível determinar a probabilidade de a vazão se encontrar entre dois valores $a$ e $b$. Porém, visto que esses cálculos demandaram a necessidade de uma expressão analítica da função $f$, utilizou-se o programa computacional RStudio. Com esses valores levantados, foi possível analisar os métodos de dimensionamento do hidrômetro, bem como as correlações com as medições reais.

\section{Resultados e discussões}

\section{Vazões típicas das unidades habitacionais}

Partindo-se das leituras obtidas, foi possível delinear as vazões típicas de cada unidade habitacional. Entretanto, vale destacar que, antes das medições, se verificou a pressão nos pontos citados na metodologia. Os valores encontrados foram muito próximos nos três períodos e nas três medições para as duas edificações, havendo em um mesmo horário variação máxima apenas de 0,3 mca com desvio-padrão no horário máximo de 0,4 mca.

As Figuras 1 e 2 apresentam os resultados das vazões nos apartamentos dos edifícios A e B respectivamente.

Ao se avaliar a distribuição dos dados do edifício A, nota-se que a vazões mínimas em todas as unidades foram próximas e se localizaram na faixa de $0,10 \mathrm{l} / \mathrm{s}$. A vazão máxima mais recorrente foi de $0,50 \mathrm{l} / \mathrm{s}$ e se repetiu em 6 apartamentos: 203, 302, 501, 603, 703 e 801. A unidade 1101 teve a menor vazão máxima dos apartamentos analisados, com valor de 0,30 1/s. Esse fato pode ser justificado por ser o apartamento com menor pressão. Da mesma forma, o apartamento 104 apresentou a vazão mais alta $(0,70$ 1/s), que pode ser explicada pelo maior valor de pressão.

Ao se analisarem as vazões dos apartamentos do edifício B, percebe-se que a vazões mínimas em todas as unidades, assim como na edificação A, foram semelhantes, ficando na faixa de $0,10 \mathrm{l} / \mathrm{s}$, assim como a vazão máxima recorrente também foi de 0,50 1/s. Ressalta-se que em 7 habitações (401, 903, 1204, 1301, 1501, 1603 e 2002) se observou uma vazão média de 0,30 1/s.

Porém, na edificação B, a unidade que teve a menor vazão máxima foi a $203(0,30 \mathrm{l} / \mathrm{s})$, tal como o apartamento 1003 , que teve maior vazão máxima $(0,70$ 1/s), não correlacionando com os locais com pressões mais altas e mais baixas.

As Tabelas 4 e 5 apresentam a distribuição da frequência de cada uma das faixas de vazão adotadas nas edificações A e B respectivamente. Nas unidades do edifício A, 97,09\% dos casos estão nas duas primeiras 
faixas de vazões; somente a primeira faixa abrangeu 76,04\% do total. Já no edifício B, embora as duas primeiras faixas de vazões também tenham sido igualmente relevantes, contabilizando 97,69\%, a primeira faixa foi mais representativa nessa edificação, correspondendo a $83 \%$ dos eventos. As Figuras 3 e 4 apresentam o histograma do perfil de consumo das amostras.

Observa-se a predominância das vazões mais baixas. No que se refere às vazões mais altas, na edificação A a faixa de vazão com limite superior de $30 \mathrm{l} / \mathrm{min}(0,5 \mathrm{l} / \mathrm{s})$ ocorreu apenas duas vezes, enquanto na edificação B oito eventos tiveram vazões acima do limite superior.

\section{Vazões de dimensionamento}

No segundo momento, determinaram-se as vazões de projeto por meio dos métodos descritos anteriormente. Os valores obtidos para cada um dos métodos são apresentados na Tabela 6.

Observando as vazões determinadas para cada edificação, é possível verificar que as menores vazões foram as calculadas pelos métodos probabilísticos, em especial aquele que apresenta $1 \mathrm{~h} 30 \mathrm{~min}$ de horário de pico. O método da norma brasileira apresentou os maiores valores.

\section{Figura 1 - Vazões típicas das unidades habitacionais do edifício A (l/s)}

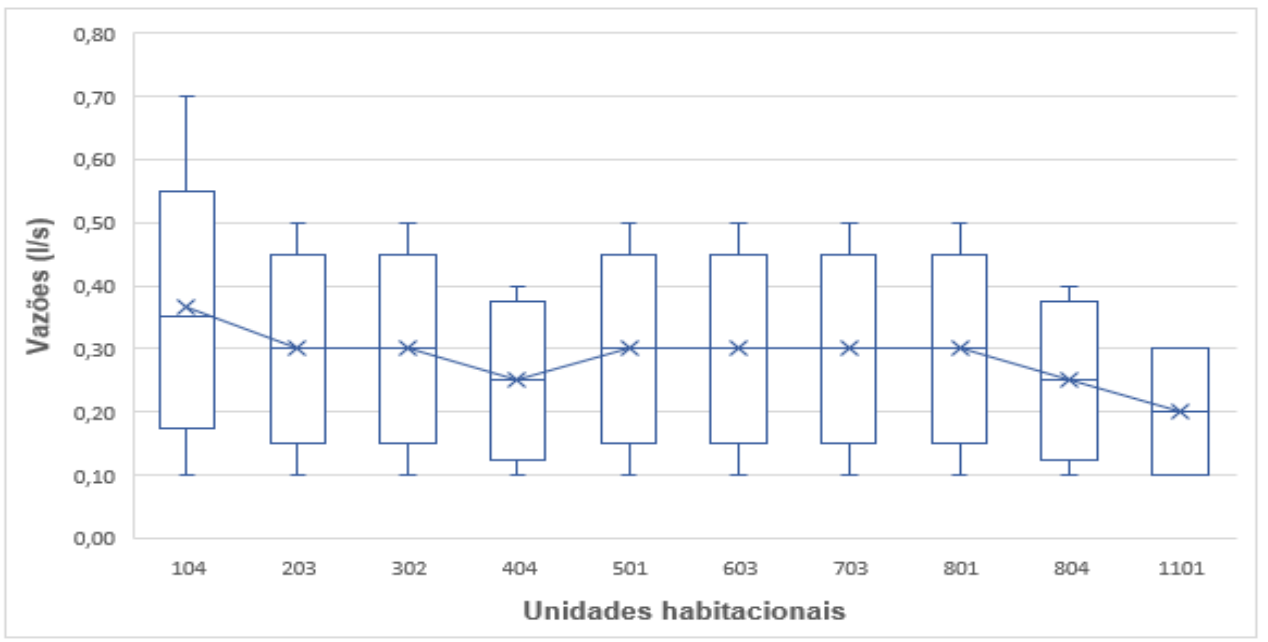

Figura 2 - Vazões típicas das unidades habitacionais do edifício B (l/s)

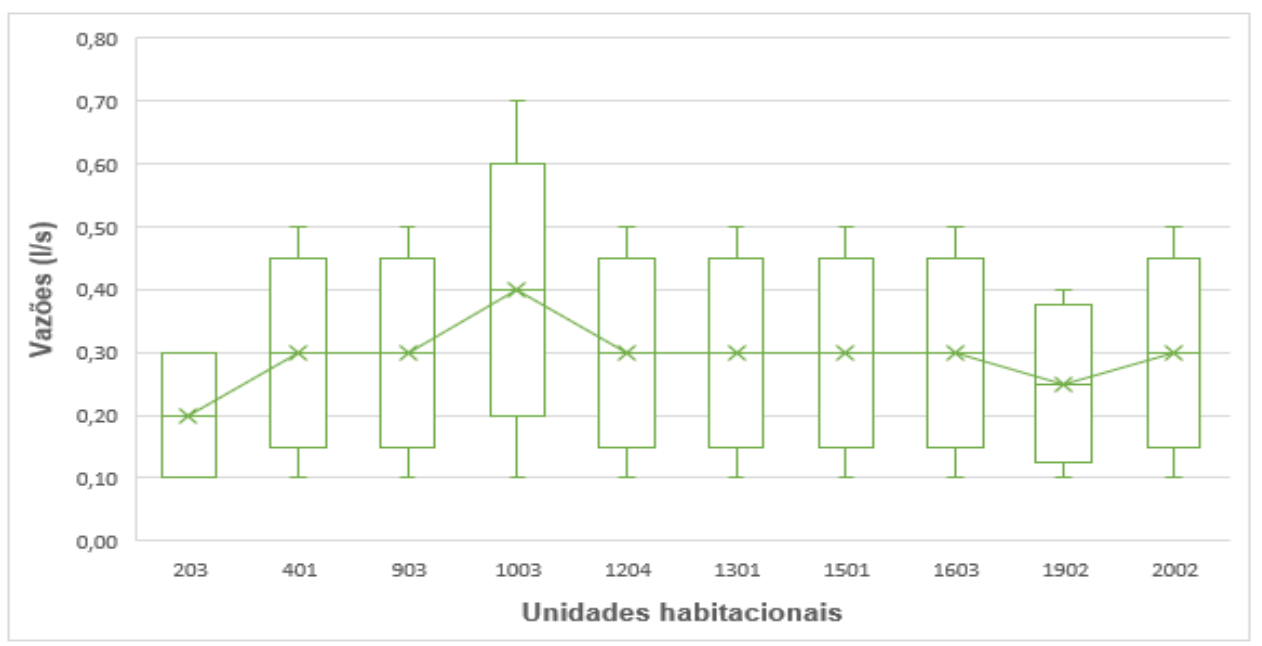


Tabela 4 - Frequência das vazões e consumo no edifício A

\begin{tabular}{|c|c|c|c|c|c|c|c|c|}
\hline \multicolumn{5}{|c|}{ Edifício A } & \multirow{3}{*}{$\begin{array}{c}\text { Data-início: } \\
\text { Frequência } \\
\text { média }\end{array}$} & \multirow{3}{*}{$\begin{array}{c}15 / 12 / 2017 \\
\text { Consumo no } \\
\text { período }\left(\mathrm{m}^{3}\right) \\
\end{array}$} & \multirow{3}{*}{$\begin{array}{c}\text { Data-fim: } \\
\text { Consumo médio } \\
\text { diário }\left(\mathrm{m}^{3}\right) \\
\end{array}$} & \multirow{3}{*}{$\begin{array}{c}\text { T5/01/2018 } \\
\text { Tempo em } \\
\text { minutos }\end{array}$} \\
\hline \multicolumn{4}{|c|}{ Intervalo de vazões } & \multirow{2}{*}{ Frequência } & & & & \\
\hline \multicolumn{2}{|c|}{$1 / \min$} & \multicolumn{2}{|c|}{$\mathbf{l} / \mathbf{s}$} & & & & & \\
\hline 0 & 6 & 0,00 & 0,10 & 184.868 & 18.487 & 150,02 & 5,00 & 31.002 \\
\hline 6 & 12 & 0,10 & 0,20 & 51.184 & 5.118 & 115,02 & 3,83 & 8.584 \\
\hline 12 & 18 & 0,20 & 0,30 & 6.117 & 612 & 22,91 & 0,76 & 1.026 \\
\hline 18 & 24 & 0,30 & 0,40 & 861 & 86 & 4,51 & 0,15 & 144 \\
\hline 24 & 30 & 0,40 & 0,50 & 77 & 8 & 0,52 & 0,02 & 13 \\
\hline 30 & 36 & 0,50 & 0,60 & - & - & - & - & - \\
\hline 36 & 42 & 0,60 & 0,70 & 2 & 0,2 & 0,02 & 0,001 & 0,34 \\
\hline 42 & 48 & 0,70 & 0,80 & - & - & - & - & - \\
\hline 48 & 54 & 0,80 & 0,90 & - & - & - & - & - \\
\hline 54 & 60 & 0,90 & 1,0 & - & - & - & - & - \\
\hline \multicolumn{4}{|c|}{ Somatório: } & 243.109 & 24.311 & 293,00 & 9,77 & $40.769,38$ \\
\hline
\end{tabular}

Tabela 5 - Frequência das vazões e consumo no edifício B

\begin{tabular}{|c|c|c|c|c|c|c|c|c|}
\hline \multicolumn{5}{|c|}{ Edifício B } & \multirow{3}{*}{$\begin{array}{c}\text { Data-início: } \\
\begin{array}{c}\text { Frequência } \\
\text { média }\end{array}\end{array}$} & \multirow{3}{*}{$\begin{array}{c}15 / 01 / 2018 \\
\text { Consumo no } \\
\text { período }\left(\mathrm{m}^{3}\right) \\
\end{array}$} & \multirow{3}{*}{\begin{tabular}{|c|} 
Data-fim: \\
$\begin{array}{c}\text { Consumo médio } \\
\text { diário }\left(\mathbf{m}^{3}\right)\end{array}$ \\
\end{tabular}} & \multirow{3}{*}{$\begin{array}{c}15 / 02 / 2018 \\
\begin{array}{c}\text { Tempo em } \\
\text { minutos }\end{array} \\
\end{array}$} \\
\hline \multicolumn{4}{|c|}{ Vazões } & \multirow{2}{*}{ Frequência } & & & & \\
\hline \multicolumn{2}{|c|}{$1 / \mathrm{min}$} & \multicolumn{2}{|c|}{$\mathbf{l} / \mathbf{s}$} & & & & & \\
\hline 0 & 6 & 0,00 & 0,10 & 148.337 & 14.834 & 132,46 & 4,42 & 24.876 \\
\hline 6 & 12 & 0,10 & 0,20 & 26.249 & 2.625 & 69,16 & 2,31 & 4.402 \\
\hline 12 & 18 & 0,20 & 0,30 & 3.540 & 354 & 15,55 & 0,52 & 594 \\
\hline 18 & 24 & 0,30 & 0,40 & 498 & 50 & 3,06 & 0,10 & 84 \\
\hline 24 & 30 & 0,40 & 0,50 & 86 & 9 & 0,68 & 0,02 & 14 \\
\hline 30 & 36 & 0,50 & 0,60 & 8 & 1 & 0 & 0,003 & 1 \\
\hline 36 & 42 & 0,60 & 0,70 & 1 & 0,1 & 0,01 & 0,0004 & 0,17 \\
\hline 42 & 48 & 0,70 & 0,80 & - & - & - & - & - \\
\hline 48 & 54 & 0,80 & 0,90 & - & - & - & - & - \\
\hline 54 & 60 & 0,90 & 1,0 & - & - & - & - & - \\
\hline \multicolumn{4}{|c|}{ Somatório: } & 178.719 & 17.872 & 221,00 & 7,37 & $29.971,18$ \\
\hline
\end{tabular}

Figura 3 - Perfil de consumo das habitações no edifício A

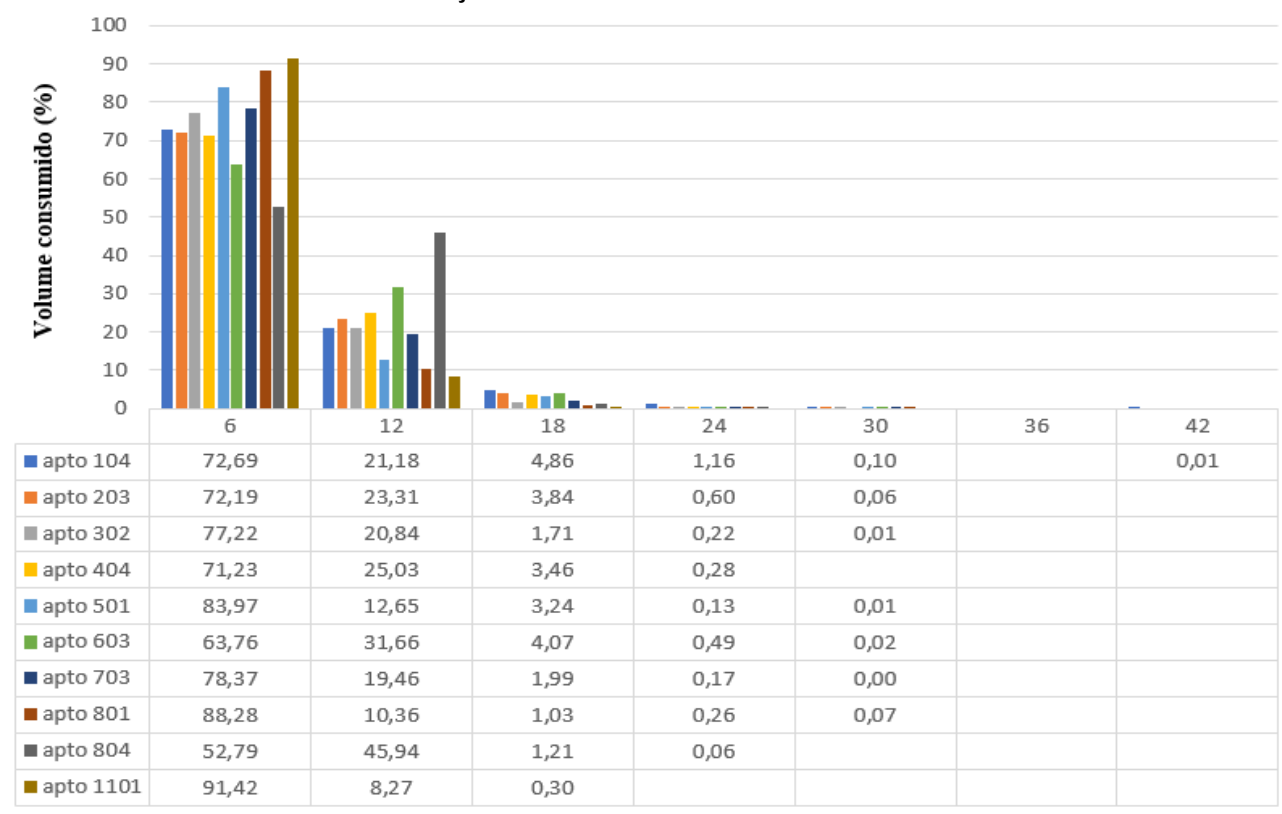

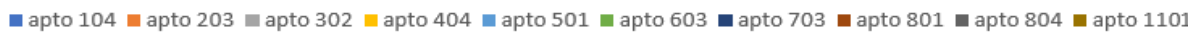

Limite superior da faixa de vazão ( $1 / \mathrm{min})$ 
Figura 4 - Perfil de consumo das habitações no edifício B

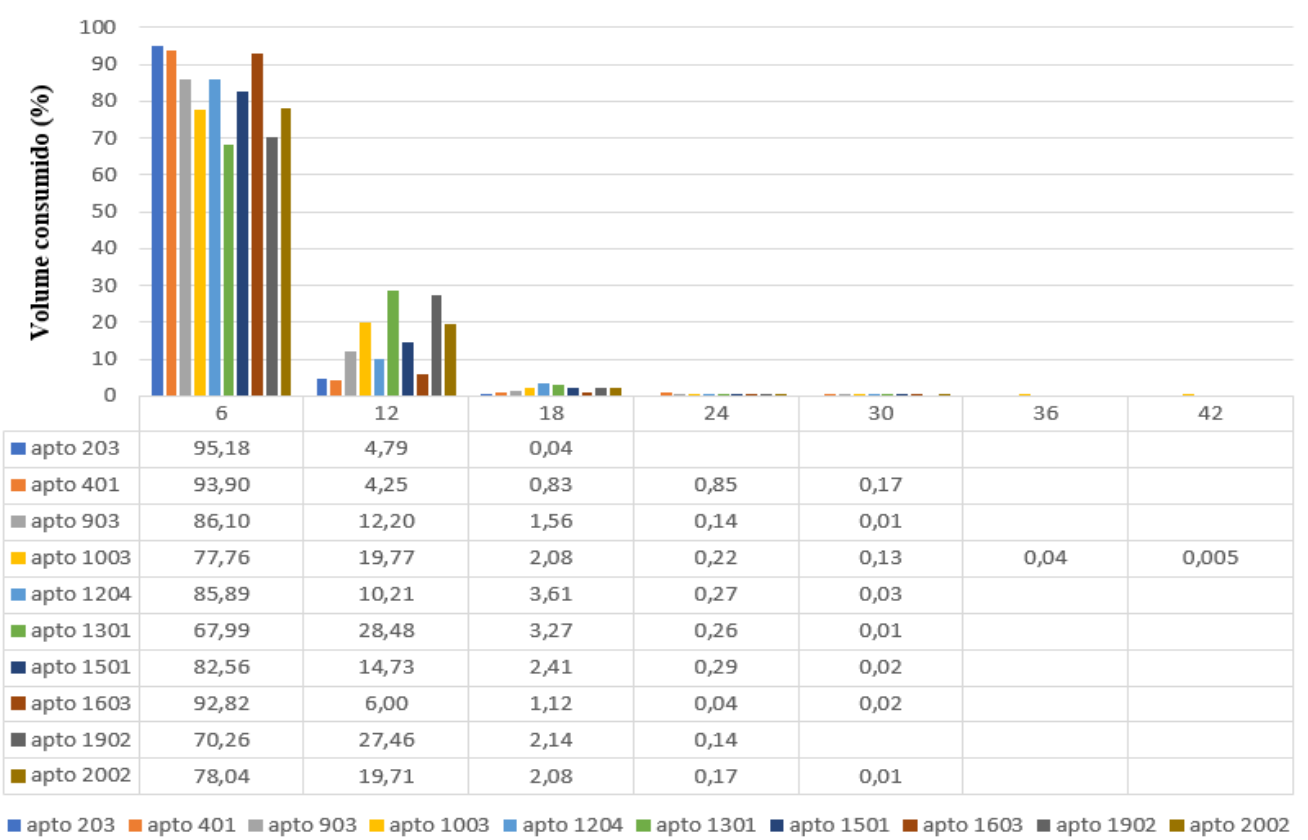

Limite superior da faixa de vazão ( $1 / \mathrm{min})$

Tabela 6 - Vazões de dimensionamento dos diferentes métodos

\begin{tabular}{l|c|c|c}
\hline \multicolumn{1}{c|}{ Local } & $\begin{array}{c}\text { Probabilístico } \\
(\mathbf{1 ~ h})\end{array}$ & $\begin{array}{c}\text { Probabilístico } \\
(\mathbf{1 ~ h ~ 3 0 ~} \mathbf{~ m i n})\end{array}$ & NBR 5626 \\
\hline Edifício A & 0,33 & 0,27 & 0,65 \\
Ap. 1101 - Edifício A & 0,66 & 0,51 & 0,93 \\
Edifício B & 0,32 & 0,27 & 0,63 \\
\hline
\end{tabular}

Ao analisar os dois resultados provenientes do método probabilístico aberto, percebe-se uma diferença que pode ser de até $0,15 \mathrm{l} / \mathrm{s}$, o que representa $22,73 \%$ da vazão original, fato do qual se pode depreender que as diferenças no período de pico passam a ser mais relevantes com o aumento significativo dos aparelhos sanitários na unidade habitacional, consequência de uma população maior fazendo uso simultâneo dos equipamentos hidráulicos. Logo, os resultados obtidos pelo método probabilístico indicaram valores de vazão inversamente proporcionais aos valores do período de pico.

\section{Escolha do hidrômetro: análises estatísticas das vazões reais e de projeto}

No processo de escolha do hidrômetro, as metodologias determinísticas da norma brasileira conduziram a um hidrômetro com vazão nominal de $2,5 \mathrm{~m}^{3} / \mathrm{h}(0,7 \mathrm{l} / \mathrm{s})$ para os apartamentos dos dois edifícios, com exceção da unidade 1101 (cobertura) do edifício A, cujo dimensionamento demandou um hidrômetro com vazão nominal de $3,5 \mathrm{~m}^{3} / \mathrm{h}(0,98 \mathrm{l} / \mathrm{s})$.

Os resultados do método probabilístico levaram à escolha de um hidrômetro com Qn igual a $2,5 \mathrm{~m}^{3} / \mathrm{h}(0,7$ 1/s) para a cobertura do edifício A e de Qn 1,5 m³/h $(0,42$ 1/s) para as demais residências. A Tabela 7 apresenta a distribuição das frequências nas classes de vazões encontradas em campo.

As médias das vazões de campo permaneceram abaixo de $0,14 \mathrm{l} / \mathrm{s}$ para todas as unidades (incluindo a cobertura duplex do edifício A), com moda e mediana de 0,1 l/s e $0,075 \mathrm{l} / \mathrm{s}$ respectivamente, conforme pode ser verificado na Tabela 8 .

Os percentis 99 (P99) ficaram inferiores a 0,48 1/s. Logo, em pelo menos 99\% dos dados as vazões nesses edifícios não ultrapassaram a vazão nominal de um hidrômetro de Qn 1,5 m³ hidrômetro como o escolhido ao se admitir a desconsideração de $1 \%$ de valores maiores do que os assinalados no P99. 
Tabela 7 - Distribuição de frequência (em \%) entre as classes de vazões (l/s)

\begin{tabular}{|c|c|c|c|c|c|c|c|c|}
\hline \multirow{2}{*}{\multicolumn{2}{|c|}{ Unidades }} & \multicolumn{7}{|c|}{ Classes $(\mathrm{l} / \mathrm{s})$} \\
\hline & & $0-0,15$ & $0,15-0,25$ & $0,25-0,35$ & $0,35-0,45$ & $0,45-0,55$ & $0,55-0,65$ & $0,65-0,75$ \\
\hline \multirow{10}{*}{ 山 } & 104 & 72,69 & 21,18 & 4,86 & 1,16 & 0,10 & - & 0,01 \\
\hline & 203 & 72,19 & 23,31 & 3,84 & 0,60 & 0,06 & - & - \\
\hline & 302 & 77,22 & 20,84 & 1,71 & 0,22 & 0,01 & - & - \\
\hline & 404 & 71,23 & 25,03 & 3,46 & 0,28 & - & - & - \\
\hline & 501 & 83,97 & 12,65 & 3,24 & 0,13 & 0,01 & - & - \\
\hline & 603 & 63,76 & 31,66 & 4,07 & 0,49 & 0,02 & - & - \\
\hline & 703 & 78,37 & 19,46 & 1,99 & 0,17 & 0,004 & - & - \\
\hline & 801 & 88,28 & 10,36 & 1,03 & 0,26 & 0,07 & - & - \\
\hline & 804 & 52,79 & 45,94 & 1,21 & 0,06 & - & - & - \\
\hline & 1101 & 91,42 & 8,27 & 0,30 & - & - & - & - \\
\hline \multirow{10}{*}{ 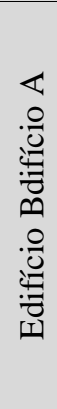 } & 203 & 95,18 & 4,79 & 0,04 & - & - & - & - \\
\hline & 401 & 93,90 & 4,25 & 0,83 & 0,85 & 0,17 & - & - \\
\hline & 903 & 86,10 & 12,20 & 1,56 & 0,14 & 0,01 & - & - \\
\hline & 1003 & 77,76 & 19,77 & 2,08 & 0,22 & 0,13 & 0,04 & 0,005 \\
\hline & 1204 & 85,89 & 10,21 & 3,61 & 0,27 & 0,03 & - & - \\
\hline & 1301 & 67,99 & 28,48 & 3,27 & 0,26 & 0,01 & - & - \\
\hline & 1501 & 82,56 & 14,73 & 2,41 & 0,29 & 0,02 & - & - \\
\hline & 1603 & 92,82 & 6,00 & 1,12 & 0,04 & 0,02 & - & - \\
\hline & 1902 & 70,26 & 27,46 & 2,14 & 0,14 & - & - & - \\
\hline & 2002 & 78,04 & 19,71 & 2,08 & 0,17 & 0,01 & - & - \\
\hline
\end{tabular}

Tabela 8 - Estatísticas descritivas das vazões de campo (l/s)

\begin{tabular}{|c|c|c|c|c|c|c|c|c|c|c|c|}
\hline \multicolumn{2}{|c|}{ Unidades } & Moda & Média & Mediana & P99 & \multicolumn{2}{|c|}{ Unidades } & Moda & Média & Mediana & P99 \\
\hline \multirow{10}{*}{ 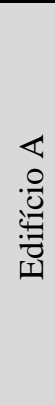 } & 104 & 0,10 & 0,117 & 0,075 & 0,373 & \multirow{10}{*}{ 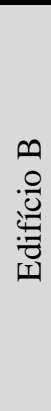 } & 203 & 0,10 & 0,105 & 0,075 & 0,230 \\
\hline & 203 & 0,10 & 0,115 & 0,075 & 0,341 & & 401 & 0,10 & 0,109 & 0,075 & 0,352 \\
\hline & 302 & 0,10 & 0,106 & 0,075 & 0,303 & & 903 & 0,10 & 0,116 & 0,075 & 0,295 \\
\hline & 404 & 0,10 & 0,115 & 0,075 & 0,329 & & 1003 & 0,10 & 0,125 & 0,075 & 0,321 \\
\hline & 501 & 0,10 & 0,099 & 0,075 & 0,323 & & 1204 & 0,10 & 0,118 & 0,075 & 0,431 \\
\hline & 603 & 0,10 & 0,125 & 0,075 & 0,338 & & 1301 & 0,10 & 0,136 & 0,075 & 0,328 \\
\hline & 703 & 0,10 & 0,104 & 0,075 & 0,309 & & 1501 & 0,10 & 0,121 & 0,075 & 0,321 \\
\hline & 801 & 0,10 & 0,091 & 0,075 & 0,285 & & 1603 & 0,10 & 0,108 & 0,075 & 0,266 \\
\hline & 804 & 0,10 & 0,135 & 0,075 & 0,272 & & 1902 & 0,10 & 0,132 & 0,075 & 0,310 \\
\hline & 1101 & 0,10 & 0,086 & 0,075 & 0,242 & & 2002 & 0,10 & 0,124 & 0,075 & 0,310 \\
\hline
\end{tabular}

Dessa forma, avaliando os três critérios ( $\mathrm{a}, \mathrm{b}$ e c) para a seleção de hidrômetros apresentados na Metodologia, os critérios (a) e (b) estariam atendidos. Porém, sob essa perspectiva, para atender ao critério (b) na unidade 1204, deveria ser instalado o medidor de vazão nominal imediatamente superior $\left(2,5 \mathrm{~m}^{3} / \mathrm{h}\right)$. Entretanto, pela ótica da porcentagem de frequência, apresentada na Tabela 7, essa unidade poderia também receber o medidor de Qn 1,5 m³/h, devido a apenas $0,03 \%$ das vazões terem ocorrido em faixas que contemplaram valores acima da vazão nominal desse hidrômetro.

As estatísticas descritivas apresentadas na Tabela 8 não permitiram concluir algo significativo em relação ao critério (c), tal como foi possível em relação aos critérios (a) e (b). Isso ocorreu porque a classe inferior de vazões $(0-0,15)$ é demasiado larga, incorporando desde valores abaixo da vazão mínima até valores consideravelmente acima da vazão de transição.

Sendo assim, para identificar qual proporção das vazões estaria violando a vazão mínima do medidor, bem como calcular a probabilidade de violação de (a), recorreu-se à modelagem probabilística dos dados utilizando-se a estimativa de densidade Kernel, conforme descrito na metodologia. As Figuras 5 e 6 apresentam as densidades Kernel ajustadas para todas as unidades dos edifícios A e B respectivamente. 
Figura 5 - Gráfico das densidades Kernel das unidades no edifício A
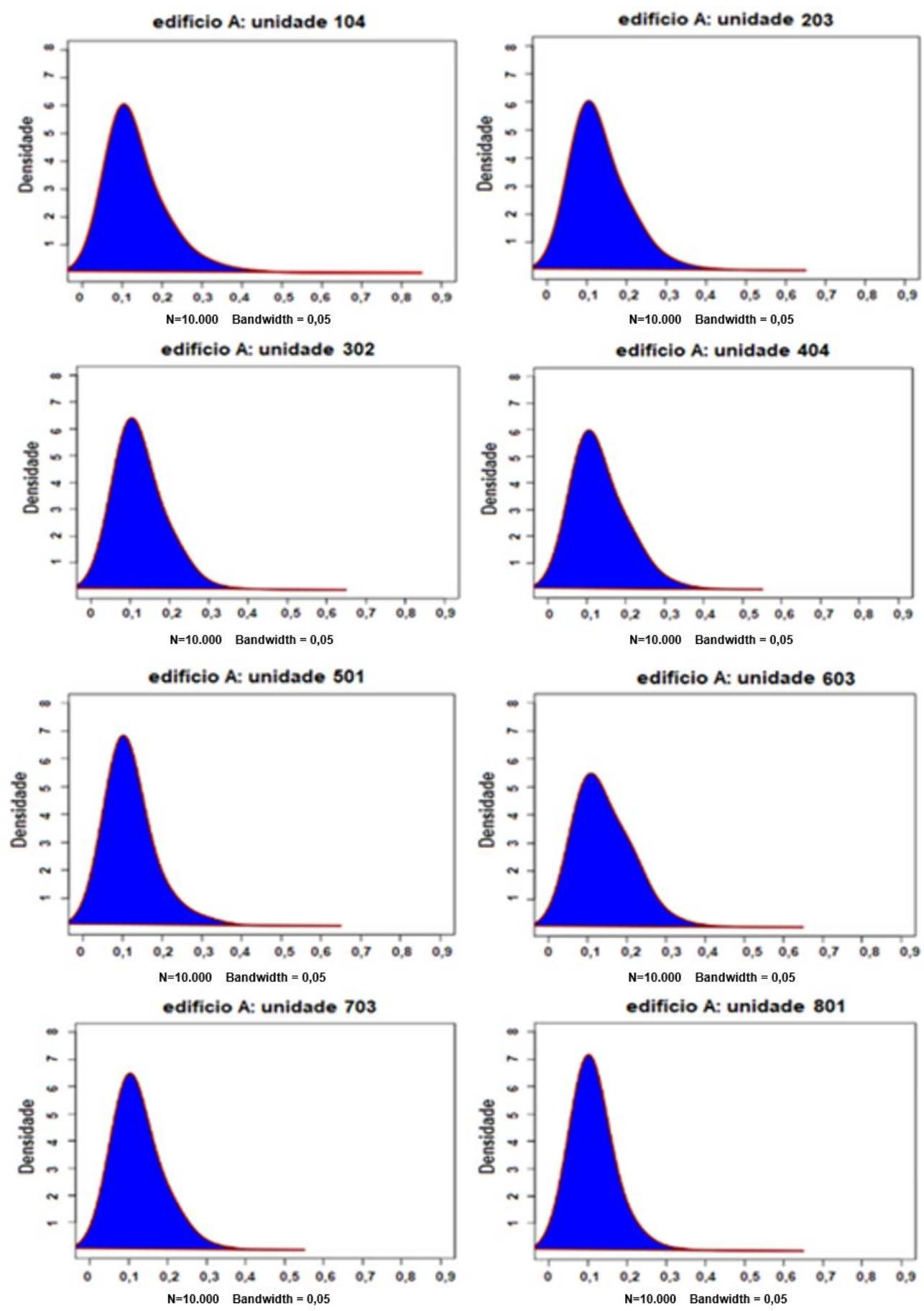

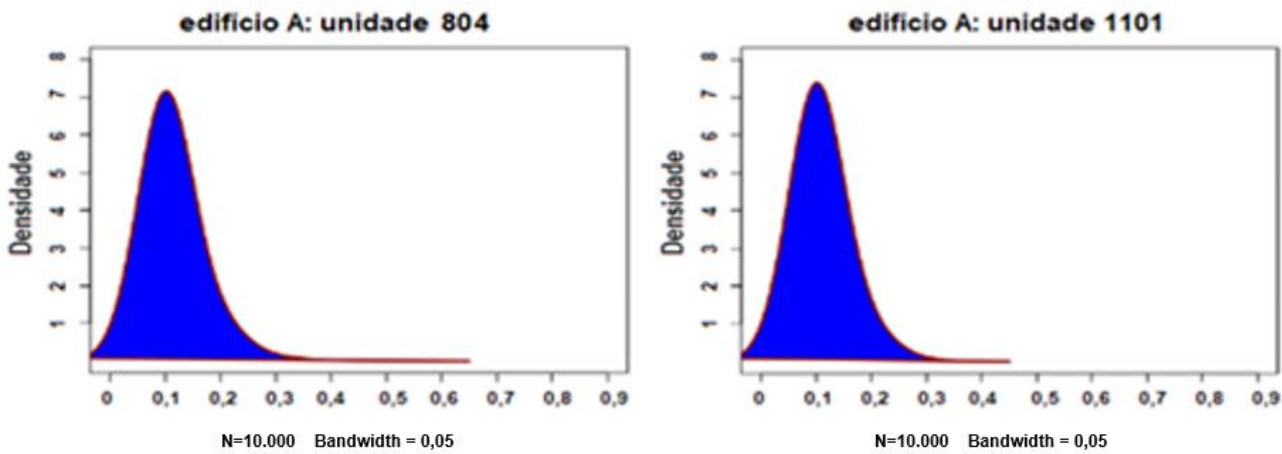

Figura 6 - Gráfico das densidades Kernel das unidades no edifício B
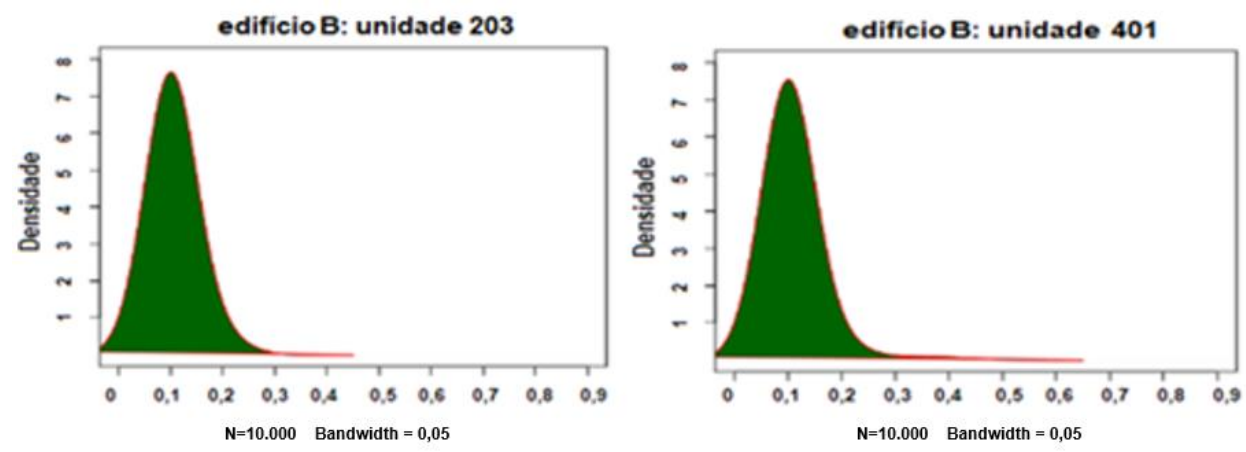

edificio B: unidade 903
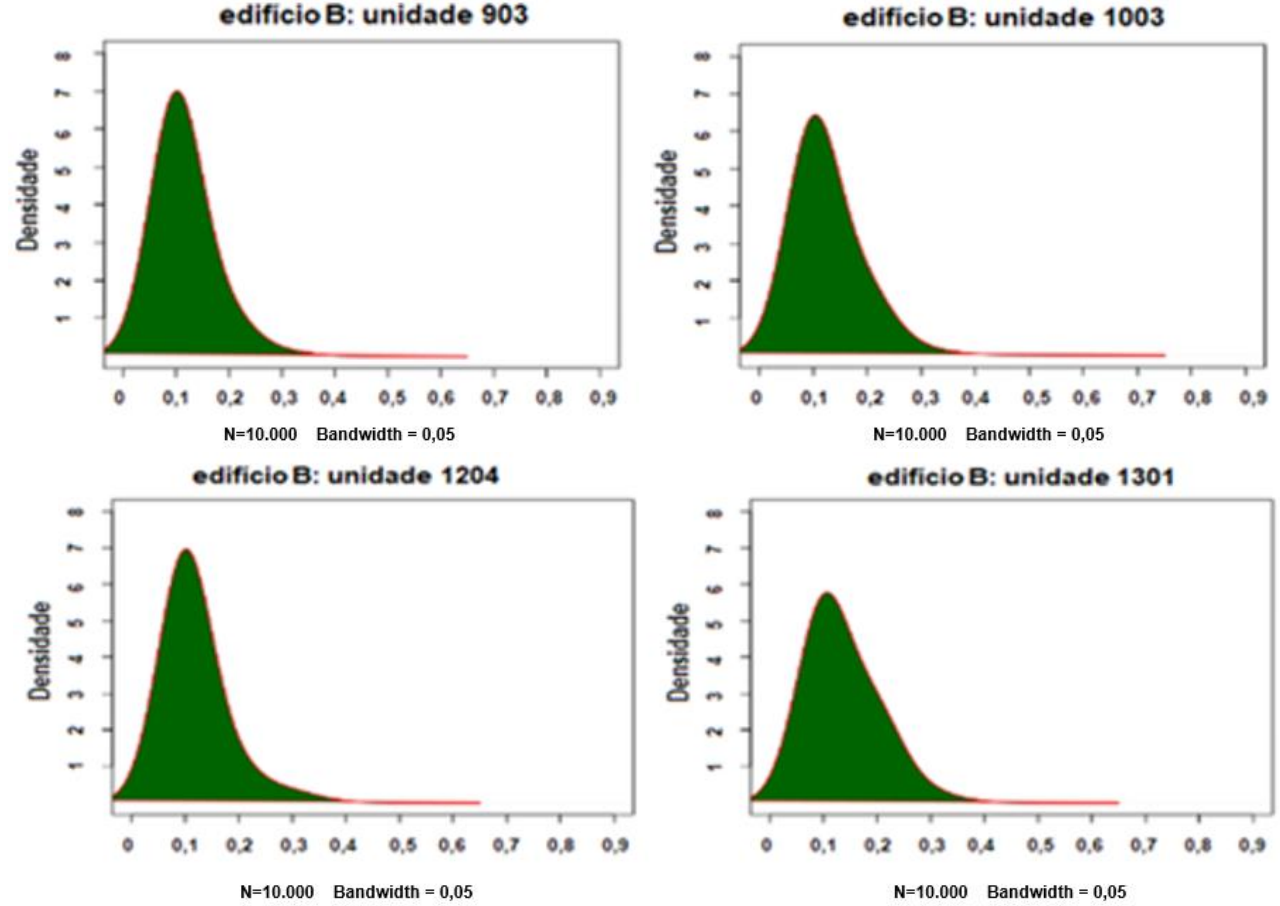

$\mathrm{N}=\mathbf{1 0 . 0 0 0}$ Bandwidth $=0,05$
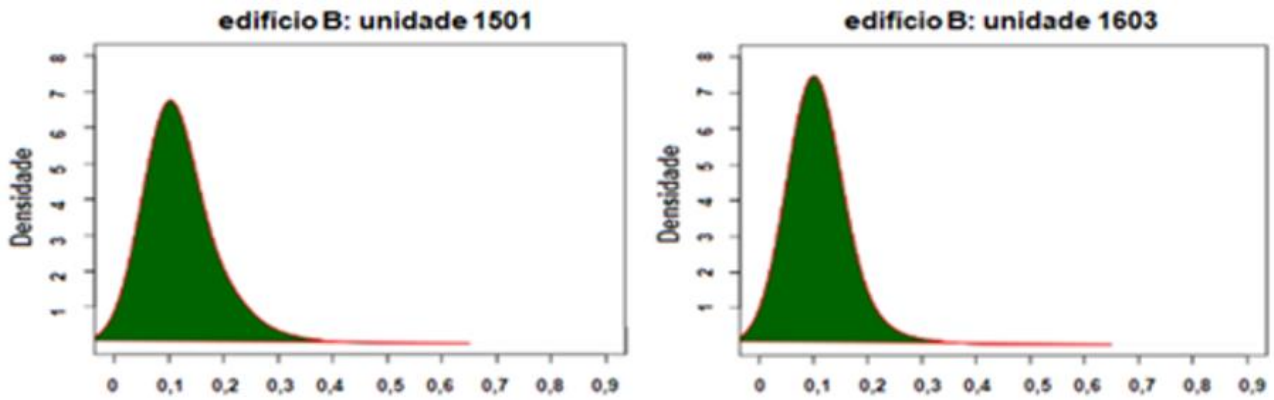

$\mathrm{N}=10.000 \quad$ Bandwidth $=0,05$

$\mathrm{N}=10.000 \quad$ Bandwidth $=0,05$ 

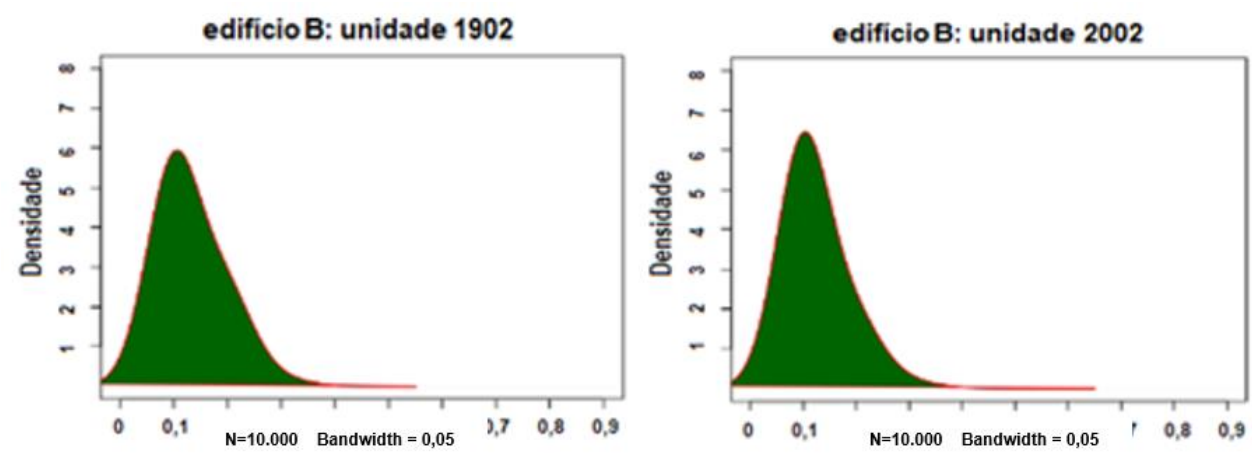

Em relação à curtose, houve diferenças mais significativas. Nos apartamentos 104, 203, 302, 404, 501 e 603 do edifício A e 1204, 1301, 1501 e 1902 do edifício B, vazões a partir de 0,4 1/s apresentaram probabilidades de ocorrência próximas a zero, enquanto nas unidades 703, 801 e 1101 do edifício A e 203, 401 e 903 do edifício $\mathrm{B}$ o mesmo ocorreu a partir da vazão 0,3 1/s.

Esse comportamento ilustra que a incidência de vazões mais elevadas no edifício $\mathrm{B}$, as quais poderiam comprometer o bom funcionamento do hidrômetro, é ainda mais rara que no edifício A. Além disso, algumas densidades ficaram com o pico acima de 7 , divergindo da maioria, que apresentou um pico em torno de 6. Isso significa que na maior parte das unidades as chances de se observarem vazões reais que se encontrem na vizinhança de $0,1 \mathrm{l} / \mathrm{s}$ são maiores que nas demais, ou seja, espera-se maior incidência de vazões no intervalo de 0,08 a $0,12 \mathrm{l} / \mathrm{s}$.

Algumas densidades Kernel apresentaram também diferenças quanto à forma, especificamente, o apartamento 603 no edifício A e o 1301 no edifício B, divergindo das demais. Nota-se que nessas unidades a taxa com que as probabilidades variam em determinados intervalos não segue o mesmo padrão. No entanto, entre $0,1 \mathrm{l} / \mathrm{s}$ a $0,2 \mathrm{l} / \mathrm{s}$, a taxa com que a probabilidade cai obedece a um padrão semelhante ao verificado na maioria das unidades e esperado para fenômenos que apresentam comportamento normal (gaussiano).

Contudo, de 0,2 1/s a 0,3 1/s, o decaimento na probabilidade é "freado" em comparação com o observado no intervalo anterior. Isto significa que nessas unidades a queda nas chances de se verificarem vazões nessa faixa é menor em relação ao observado nas outras unidades.

A Figura 7 apresenta as estimativas de densidades Kernel para os dois edifícios (A em azul, B em verde) e para a unidade 1101, cobertura do edifício A (em vermelho).

Verifica-se que as distribuições de probabilidade estimadas pelo kernel gaussiano são visualmente parecidas nos dois edifícios. Contudo, percebe-se que no edifício B as vazões em torno de 0,1 1/s apresentam maior probabilidade de ocorrência do que no edifício $\mathrm{A}$.

A unidade 1101 destoa das demais na edificação A. Assinala-se também que, para essa unidade, as probabilidades de ocorrência de vazões em torno de 0,1 1/s são maiores que as estimadas para o edifício B.

A Tabela 9 apresenta as probabilidades obtidas para ocorrerem vazões inferiores às mínimas e de transição e máxima. Observa-se que, em ambos os hidrômetros considerados (classes B e C), a probabilidade de se obterem vazões superiores às máximas é nula.

Isso corrobora com as análises anteriores sobre o cumprimento da recomendação (a). Além disso, na escolha do hidrômetro de Qn $1,5 \mathrm{~m}^{3} / \mathrm{h}(0,42 \mathrm{l} / \mathrm{s})$ se observa uma redução da proporção das vazões que violam $o$ critério (c).

Figura 7 - Densidades Kernel dos edifícios A e B e unidade 1101 


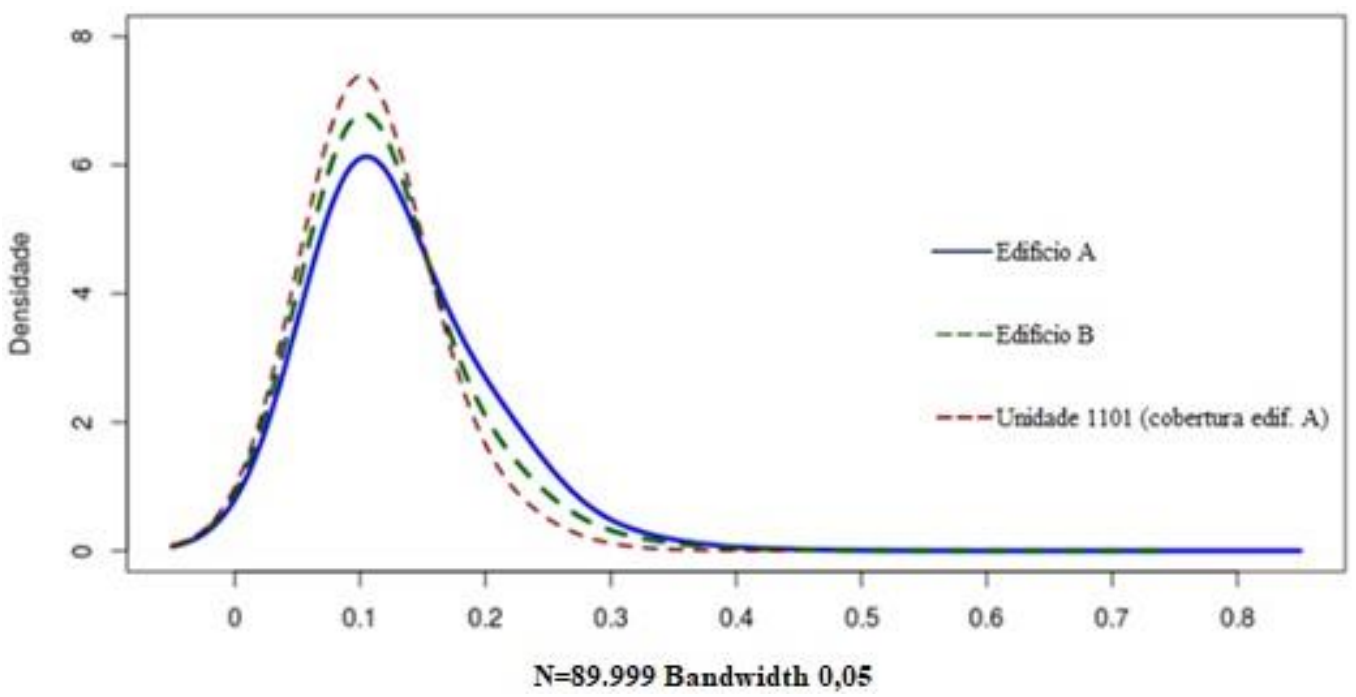

Tabela 9 - Probabilidades para a avaliação dos hidrômetros de Qn = 1,5 m³ $/ \mathrm{h}$ e 2,5 m³/h (\%) (arrumar na imagem: $1,5 \mathrm{~m}^{3} / \mathrm{h} / 2,5 \mathrm{~m}^{3} / \mathrm{h}$ )

\begin{tabular}{|c|c|c|c|c|c|}
\hline \multicolumn{2}{|c|}{ Local } & Hidrômetro & $\begin{array}{c}\text { Vazão< } \\
\text { Qmin }\end{array}$ & $\begin{array}{l}\text { Vazão< } \\
\text { Qtrans }\end{array}$ & $\begin{array}{l}\text { Vazão } \\
\text { >Qmáx }\end{array}$ \\
\hline \multirow{6}{*}{ 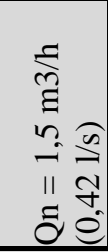 } & \multirow{2}{*}{ Ed. A } & $\mathrm{B}$ & 2,543674 & 6,932626 & 0 \\
\hline & & $\mathrm{C}$ & 1,986156 & 2,159953 & 0 \\
\hline & \multirow{2}{*}{ Ed. B } & $\mathrm{B}$ & 2,823112 & 7,833714 & 0 \\
\hline & & $\mathrm{C}$ & 2,265211 & 2,440477 & 0 \\
\hline & \multirow{2}{*}{$\begin{array}{c}\text { Un } 1101 \\
\text { Ed. A }\end{array}$} & B & 2,997034 & 8,498732 & 0 \\
\hline & & $\mathrm{C}$ & 2,49291 & 2,735799 & 0 \\
\hline \multicolumn{2}{|c|}{ Local } & Hidrômetro & $\begin{array}{c}\text { Vazão< } \\
\text { Qmin }\end{array}$ & $\begin{array}{l}\text { Vazão< } \\
\text { Qtrans }\end{array}$ & $\begin{array}{c}\text { Vazão } \\
\text { >Qmáx }\end{array}$ \\
\hline \multirow{6}{*}{ 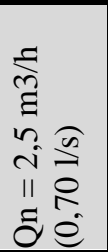 } & \multirow{2}{*}{ Ed. A } & $\mathrm{B}$ & 3,217803 & 14,47344 & 0 \\
\hline & & $\mathrm{C}$ & 2,345627 & 2,75464 & 0 \\
\hline & \multirow{2}{*}{ Ed. B } & B & 3,484128 & 16,61951 & 0 \\
\hline & & $\mathrm{C}$ & 2,626278 & 3,031402 & 0 \\
\hline & \multirow{2}{*}{$\begin{array}{c}\text { Un } 1101 \\
\text { Ed. A }\end{array}$} & B & 3,900427 & 18,07718 & 0 \\
\hline & & $\mathrm{C}$ & 2,864067 & 3,2777563 & 0 \\
\hline
\end{tabular}

Ressalta-se que o hidrômetro de Qn $1,5 \mathrm{~m}^{3} / \mathrm{h}$ atenderia até mesmo à unidade 1101 do edifício A ao se verificarem as vazões de campo, embora esse não tenha sido sugerido por nenhum dos métodos. Porém, considerando-se que os parâmetros fundamentais para a seleção de hidrômetros são a pressão e a vazão, atentando-se às perdas de carga dos hidrômetros, esse equipamento não poderia ser utilizado na cobertura, conforme demonstram os cálculos de perda de carga dos medidores. No entanto, esse hidrômetro não apresentaria problema em nenhuma outra amostra estudada.

Ainda em relação à cobertura do edifício A, as simulações probabilísticas indicaram o hidrômetro de Qn 2,5 $\mathrm{m}^{3} / \mathrm{h}$, o que nesse caso mostrou-se mais adequado, corroborando com a predileção por essa metodologia de dimensionamento em relação à apresentada atualmente na NBR 5626 (ABNT, 1998), conforme apontado pelas ponderações realizadas.

Avaliando-se separadamente os hidrômetros, a partir das classes metrológicas, nota-se que o medidor do tipo C apresenta menor probabilidade de experimentar vazões que estejam abaixo de sua vazão mínima em comparação com um hidrômetro do tipo B.

Portanto, diante da recomendação de uso do hidrômetro de Qn 1,5 m³/h - indicado pelas medições reais e obtido a partir do método probabilístico -, hidrômetros do tipo $\mathrm{C}$ apresentam redução de aproximadamente $20 \%$ na proporção do tempo em que as vazões estarão abaixo da vazão mínima do medidor. 
Por outro lado, a adoção de um hidrômetro do tipo $\mathrm{C}$ em detrimento de um do tipo B representaria, nessas condições, uma redução de aproximadamente $82 \%$ na proporção de vazões abaixo da vazão de transição. Logo, considerando esse resultado e o anterior, demonstra-se que um hidrômetro do tipo C apresenta um ganho comparativo significativo em termos de diminuição na proporção de possíveis submedições.

Assim, diante das análises estatísticas das vazões de campo e de projeto, em conjunto com os demais parâmetros apontados, a Tabela 10 resume os resultados relativos a cada abordagem no dimensionamento do hidrômetro.

Observando os hidrômetros apontados em cada método de dimensionamento, foi possível perceber que, em comparação com as medições reais, as vazões apontadas pela técnica determinística provocaram o superdimensionamento dos medidores nas unidades das duas edificações.

A utilização de medidores da classe $\mathrm{C}$ de Qn 1,5 m³/h resultaria em ganho de desempenho metrológico, minimizando a submedição em edifícios multipavimentos com as mesmas características das amostras retratadas neste estudo.

Verificou-se também as probabilidades de ocorrerem vazões de dimensionamento em cada apartamento, as quais podem ser vistas na Tabela 11

Observa-se que os valores mais altos são relativos ao método probabilístico (período de pico de $1 \mathrm{~h} 30 \mathrm{~min}$ ), o qual ultrapassou 5\% em 3 unidades do edifício A (104, 203 e 603); e, para os demais métodos, a probabilidade foi inferior a $3 \%$.

Tabela 10 - Dimensionamento do hidrômetro pelos métodos pesquisados

\begin{tabular}{c|c|c|c}
\hline Métodos & $\begin{array}{c}\text { Unidades padrão } \\
\text { edifício A }\end{array}$ & $\begin{array}{c}\text { Unidades padrão } \\
\text { edifício B }\end{array}$ & $\begin{array}{c}\text { Cobertura edifício } \\
\text { A }\end{array}$ \\
\hline Probabilístico $1 \mathrm{~h}$ & HD Qn $1,5 \mathrm{~m}^{3} / \mathrm{h}$ & HD Qn $1,5 \mathrm{~m}^{3} / \mathrm{h}$ & HD Qn $2,5 \mathrm{~m}^{3} / \mathrm{h}$ \\
Probabilístico $1 \mathrm{~h} 30 \mathrm{~min}$ & HD Qn $1,5 \mathrm{~m}^{3} / \mathrm{h}$ & HD Qn $1,5 \mathrm{~m}^{3} / \mathrm{h}$ & HD Qn $2,5 \mathrm{~m}^{3} / \mathrm{h}$ \\
NBR 5626:1998 & HD Qn $2,5 \mathrm{~m}^{3} / \mathrm{h}$ & HD Qn $2,5 \mathrm{~m}^{3} / \mathrm{h}$ & HD Qn $3,5 \mathrm{~m}^{3} / \mathrm{h}$ \\
Vazões de campo & HD Qn $1,5 \mathrm{~m}^{3} / \mathrm{h}$ & HD Qn $1,5 \mathrm{~m}^{3} / \mathrm{h}$ & HD Qn $2,5 \mathrm{~m}^{3} / \mathrm{h}$ \\
\hline
\end{tabular}

Tabela 11 - Probabilidades de a vazão de dimensionamento ocorrer no escopo das medições reais (\%)

\begin{tabular}{|c|c|c|c|c|c|c|c|}
\hline \multicolumn{4}{|c|}{ Edifício $\mathbf{A}$} & \multicolumn{4}{|c|}{$\begin{array}{c}\text { Edifício B } \\
\end{array}$} \\
\hline & $\begin{array}{c}\text { Probabilístico } \\
1 \mathrm{~h}\end{array}$ & $\begin{array}{c}\text { Probabilístico } \\
1 \text { h } 30 \mathrm{~min}\end{array}$ & NBR 5626 & & $\begin{array}{c}\text { Probabilístico } \\
1 \mathrm{~h}\end{array}$ & $\begin{array}{c}\text { Probabilístico } \\
1 \text { h } 30 \mathrm{~min}\end{array}$ & NBR 5626 \\
\hline Unidades & $(\mathbf{0 , 3 3} \mathrm{l} / \mathrm{s})$ & $(0,27$ l/s) & $(0,65$ l/s $)$ & Unidades & $(\mathbf{0 , 3 2} \mathrm{l} / \mathrm{s})$ & $(0,27$ l/s $)$ & $(0,63$ l/s $)$ \\
\hline 104 & 2,59480950 & 6,48479110 & 0,00848510 & 203 & 0,05183520 & 0,43427800 & 0 \\
\hline 203 & 1,74950160 & 5,30816330 & 0 & 401 & 1,28383090 & 1,98499650 & 0,00053280 \\
\hline 302 & 0,76612660 & 3,14610190 & 0 & 903 & 0,76101880 & 2,27417810 & 0,00003150 \\
\hline 404 & 1,31264180 & 4,79069630 & 0 & 1003 & 1,23490120 & 3,46082600 & 0,01124540 \\
\hline 501 & 1,05892230 & 3,51331380 & 0 & 1204 & 1,57713130 & 3,74645930 & 0,00009420 \\
\hline 603 & 1,70803880 & 5,98551810 & 0 & 1301 & 1,57461850 & 4,91662010 & 0,00003170 \\
\hline 703 & 0,78658340 & 3,17923640 & 0 & 1501 & 1,21765710 & 3,24749980 & 0,00006300 \\
\hline 801 & 0,63259040 & 1,92549370 & 0 & 1603 & 0,48099150 & 1,37643250 & 0,00006260 \\
\hline 804 & 0,59505340 & 4,60137740 & 0 & 1902 & 1,06902220 & 3,89040760 & 0 \\
\hline $\begin{array}{c}1101 \\
\text { (cobertura) }\end{array}$ & $\begin{array}{c}0 \\
(\mathrm{Q}=0,66 \mathrm{l} / \mathrm{s})\end{array}$ & $\begin{array}{c}0 \\
(\mathrm{Q}=0,51 \mathrm{l} / \mathrm{s})\end{array}$ & $\begin{array}{c}0 \\
\mathrm{Q}=0,93 \mathrm{l} / \mathrm{s})\end{array}$ & 2002 & 1,02208260 & 3,27377410 & 0,00003150 \\
\hline
\end{tabular}

Ademais, aponta-se que a vazão de dimensionamento determinada pelo método da norma brasileira apresentou probabilidade inferior a 0,01\% (exceto pela unidade 1003) de ocorrer. Logo, as chances de a vazão ser pelo menos igual ao valor dimensionado são de no máximo 1 em 10.000.

Por fim, após todas as considerações, demonstrou-se que o método da raiz quadrada apresentado na NBR 5626 (ABNT, 1998) pode resultar em superestimativa das vazões de projeto nos ramais de alimentação de sistemas de medição individualizada. Dessa forma, corroborado pelas análises anteriores, o método probabilístico foi apresentado como a melhor opção para o dimensionamento da vazão. 


\section{Conclusões}

A presente pesquisa analisou técnicas de dimensionamento de hidrômetros em relação a medições reais, escolhendo-se métodos representativos de determinação de vazão de projeto -raiz quadrada, apresentado pela NBR 5626 (ABNT, 1998), e probabilístico, proposto por Gonçalves (1986) -, e fez o levantamento de campo em 20 unidades habitacionais distribuídas igualmente em duas edificações multifamiliares, de planta baixa similar, identificando-se as vazões de abastecimento.

Em relação às vazões de projeto nas unidades-tipo, pôde-se concluir que os procedimentos da NBR 5626 (ABNT, 1998) apresentaram aproximadamente o dobro dos valores indicados pelo método probabilístico.

$\mathrm{Na}$ etapa de campo, predominaram as vazões mais baixas catalogadas no estudo (faixa de $0,10 \mathrm{l} / \mathrm{s}$ ), com intervalo de vazões máximas e mínimas idênticas nas edificações A e B, variando de 0,10 1/s a 0,70 1/s, com vazão máxima recorrente de 0,50 l/s.

Considerando-se todo o contexto, as medições reais apontaram para as unidades padrão o hidrômetro de Qn 1,5 m³ h e de Qn 2,5 m³/h para a cobertura, pois, embora o hidrômetro de Qn 1,5 m³/h encaixasse nas faixas de vazões encontradas na unidade 1101 do edifício A, não poderia ser utilizado por causa da perda de carga.

Concluiu-se que, estatisticamente, medidores bem dimensionados certificam o aumento do volume micromedido para a concessionária local, bem como minoram a interferência do superdimensionamento. Além disso, o uso do medidor adequado aumenta a vida útil e reduz os custos de manutenção e substituição, assim como a adoção de hidrômetros de classe metrológica $\mathrm{C}$ apresenta ganhos pela redução dos eventos de submedição.

Neste estudo também se confirmou o método probabilístico como o mais assertivo, corroborando com a revisão de literatura. No entanto, o dimensionamento pela técnica probabilística requer o uso de muitas variáveis e, por isso, é primordial a utilização de um software específico para viabilizar os cálculos, razão pela qual haveria a necessidade de investimentos para a implantação do método e de treinamento de profissionais projetistas pela concessionária local, o que também demandaria tempo considerável.

O conhecimento do perfil de consumo do usuário - o qual é necessário para que a prestadora dos serviços de saneamento conheça seus clientes - permite que se diminuam perdas no faturamento e se incentivem medidas para o uso racional da água.

Por fim, ao se realizar um levantamento de campo, identificando as vazões de abastecimento e as faixas de maior consumo, serão geradas informações que, por meio de parâmetros consistentes, permitirão melhorias nos procedimentos de avaliação do dimensionamento dos medidores, assim como colaborarão para que a área de micromedição da empresa de saneamento local amplie seu banco de dados, auxiliando diagnósticos operacionais.

Enfim, este estudo pode subsidiar outras pesquisas em diferentes regiões do país, podendo ser replicado por outras companhias de saneamento para a melhoria da gestão da micromedição. Dessa forma, para o desenvolvimento de trabalhos futuros, recomendam-se

(a) a reprodução deste estudo em outras edificações multifamiliares em diferentes áreas da cidade de Goiânia e de outras cidades brasileiras, com configurações diversas, a fim de se traçar o perfil por região; e

(b) a avaliação econômica da substituição dos hidrômetros velocimétricos de classe metrológica B por hidrômetros volumétricos de classe $\mathrm{C}$.

\section{Referências}

ALVISI, S.; FRANCHINI, M. A procedure for the design of district metered areas in water distribution systems. Procedia Engineering, v. 70, p. 41-50, 2014.

ASSOCIAÇÃO BRASILEIRA DE NORMAS TÉCNICAS. NBR 15538: medidores de água potável: ensaios para avaliação de eficiência. Rio de Janeiro, 2014.

ASSOCIAÇÃO BRASILEIRA DE NORMAS TÉCNICAS. NBR 5626: instalação predial de água fria. Rio de Janeiro, 1998.

BARRETO, D.; MEDEIROS, O. Caracterização da vazão e frequência de uso de aparelhos sanitários. Ambiente Construído, Porto Alegre, v. 8, n. 4, p. 137-149, out./dez. 2008. 
COELHO, A. C.; MAYNARD, J. C. B. Medição individualizada de água em apartamentos. Recife: Comunicarte, 1999.

DE PAOLA, F. et al. Automatic multi-objective sectorization of a water distribution network. Procedia Engineering, v. 89, p. 1200-1207, 2014a.

DE PAOLA, F. et al. Optimal design of district metered areas in water distribution networks. Procedia Engineering, v. 70, p. 449-457, 2014b.

DI NARDO, A. et al. Divide and conquer partitioning techniques for smart water networks. Water, v. 89, p. 1176-1183, 2014.

EUROPEAN COMMITTEE FOR STANDARDIZATION. EN 806-3: specifications for installations inside buildings conveying water for human consumption: simplified method. Geneva, 2006.

GOMES, R.; SOUSA, J.; MARQUES, A. S. Influence of future water demand patterns on the district metered areas design and benefits yielded by pressure management. Procedia Engineering, v. 70, p. $744-$ 752, 2014.

GOMES, R. et al. Different design criteria for district metered areas in water distribution networks. Procedia Engineering, v. 119, p. 1221-1230, 2015.

GONÇALVES, O. M. Formulação de modelo para o estabelecimento de vazões de projeto em sistemas prediais de distribuição de água fria. São Paulo, 1986. 388 f. Tese (Doutorado em Engenharia Civil) Escola Politécnica, Universidade de São Paulo, São Paulo, 1986.

HAJEBI, S. et al. Water distribution network sectorization using structural graph partitioning and multiobjective optimization. Water Practice \& Technology, v. 89, n. 2014, p. 1144-1151, 2014.

ILHA, M. S. O.; OLIVEIRA, L. H.; GONÇALVES, O. M. Design flow rate simulation of cold water supply in residential buildings by means of open probabilistic model. In: CIB W62 INTERNATIONAL SYMPOSIUM ON WATER SUPPLY AND DRAINAGE FOR BUILDINGS, Hong Kong, 2008. Proceedings [...] Hong Kong: The Hong Kong Polytechnic University, 2008.

ILHA, M. S. O.; OLIVEIRA, L. H.; GONÇALVES, O. M. Sistemas de medição individualizada de água: como determinar as vazões de projeto para a especificação dos hidrômetros? Engenharia Sanitária Ambiental, v. 15 n. 2, p. 177-186, abr./jun. 2010.

KARATHANASI, I.; PAPAGEORGAKOPOULOS, C. Development of a leakage control system at the water supply network of the city of Patras. Sensors Journal, v. 162, p. 553-558, 2016.

KORKANA, P. et al. Developing an optimization algorithm to form district metered areas in a water distribution system. Procedia Engineering, v. 162, p. 530-536, $2016 \mathrm{a}$.

KORKANA, P. et al. Forming district metered areas in a water distribution network using genetic algorithms. Sensors Journal, v. 162, p. 511-520, 2016 b.

LONDOÑO, L.; SEGRERA, J.; JARAMILLO, M. Water distribution system of Santa Marta city, Colombia. Procedia Engineering, v. 186, p. 20-27, 2017.

MINISTÉRIO DO DESENVOLVIMENTO, INDÚSTRIA E COMÉRCIO; INSTITUTO NACIONAL DE METROlOGIA, QUALIDADE E TECNOLOGIA. Portaria n 246, de 17 de outubro de 2000.

OLIVEIRA, L. H. et al. Modelling of water demand in building supply systems using fuzzy logic. Journal of Building Services Engineering Research \& Technology, v. 34, n. 2, p. 145-163, 2011.

OLIVEIRA, L. H. Fatores que influenciam as vazões de projeto em sistemas de medição individualizada de água. Hydro, São Paulo, v. 11, p. 64-67, set. 2007.

PEREIRA, L. G. Avaliação da submedição de água em edificações residenciais unifamiliares: o caso das unidades de interesse social localizadas em campinas. Campinas, 2007. 133 f. Dissertação (Mestrado em Engenharia Civil) - Faculdade de Engenharia Civil, Arquitetura e Urbanismo, Universidade Estadual de Campinas, Campinas, 2007.

PORTUGAL. Regulamento geral dos sitemas públicos e prediais de dsitribuição de água e de drenagem de águas residuais. Decreto Regulamentar no 23/95: Regulamento Geral dos Sistemas Públicos e Prediais de Distribuição de Água e de Drenagem de Águas Residuais. Diário Da República, Lisboa, 1996.

ROSS, S. Probabilidade: um curso moderno com aplicações. 8. ed. Porto Alegre: Bookman, 2010. 
RUSCA, M. et al. An interdisciplinary political ecology of drinking water quality: exploring socioecological inequalities in Lilongwe's water supply network. Geoforum, v. 84, p. 138-146, 2017.

SAVIC, D.; FERRARI, G. Design and performance of district metering areas in water distribution systems. 2014. Procedia Engineering, v. 89, p. 1136-1143, 2014.

SILVERMAN, B. W. Density estimation for Statistics and Data Analysis. 5. ed. Londres, Nova York: Chapman and Hall, 1996.

UNITED NATIONS WATER. Annual Report 2015. Genebra, 2015. UN-Water Technical Advisory Unit.

WRIGHT, R.; STOIANOV, I.; PARPAS, P. Dynamic topology in water distribution networks. Procedia Engineering, v. 70, p. 1735-1744, 2014.

\section{Agradecimentos}

Os autores agradecem a contribuição da Fundação de Amparo à Pesquisa do Estado de Goiás (Fapeg) pela concessão de bolsa de mestrado.

Os autores também agradecem ao apoio de Saneamento do Estado de Goiás (SANEAGO) pelo apoio operacional da pesquisa. 
Marina Melo Luiz Amorim

Departamento de Supervisão e Micromedição | Saneamento de Goiás S/A | Av. Ver. José Monteiro, 1953, Negrão de Lima | Goiânia - GO Brasil | CEP 74650-300 | Tel.: (62) 3269-9808 | E-mail: marinaamorim.eng@hotmail.com

\title{
Marcus André Siqueira Campos
}

Escola de Engenharia Civil e Ambiental | Universidade Federal de Goiás | Av. Universitária, Quadra 86 Área 1488, Bloco J Setor Leste Universitário | Goiânia - GO - Brasil | CEP 74605-220 | Tel.: (62) 3209-6084 | E-mail: marcus_campos@ufg.br

\author{
Ambiente Construído \\ Revista da Associação Nacional de Tecnologia do Ambiente Construído \\ Av. Osvaldo Aranha, $99-3^{\circ}$ andar, Centro \\ Porto Alegre - RS - Brasil \\ CEP $90035-190$ \\ Telefone: +55 (51) 3308-4084 \\ Fax: +55 (51) 3308-4054 \\ www.seer.ufrgs.br/ambienteconstruido \\ E-mail: ambienteconstruido@ufrgs.br
}

This is an open-access article distributed under the terms of the Creative Commons Attribution License. 